\title{
CONTEXTUALIZAC̣̃̃O NA FORMAC̣ÃO INICIAL DE PROFESSORES DE CIÊNCIAS E A PERSPECTIVA EDUCACIONAL DE PAULO FREIRE
}

\author{
Carolina dos Santos Fernandes* \\ Carlos Alberto Marques** \\ Demétrio Delizoicov ${ }^{* * *}$
}

RESUMO: Este trabalho pretende favorecer reflexões de ordem teórico-metodológica sobre práticas contextualizadas na formação inicial de professores e no ensino de ciências a partir da perspectiva educacional de Paulo Freire, tendo como base sua obra Extensão ou Comunicação?. Os elementos apontados como possibilidades de abordagem contextualizada não são conclusivos, mas, sim, reflexões que abrem caminhos para um trabalho contextualizado na formação de professores e no ensino de ciências, especialmente no que se refere a romper com uma formação pautada nos pressupostos da racionalidade técnica. Em linhas gerais, ressalta-se a contribuição da perspectiva freireana na superação de concepções extensionistas de ensino.

Palavras-chave: Formação de professores. Ensino de Ciências. Perspectiva freireana de educação.

\section{CONTEXTUALIZACIÓN EN LA FORMACIÓN INICIAL DE PROFESORES DE LAS} CIENCIAS Y LA PERSPECTIVA EDUCACIONAL DE PAULO FREIRE

RESUMEN: Este trabajo pretende favorecer reflexiones de orden teórico y metodológico sobre prácticas contextualizadas en la formación inicial de profesores y en la enseñanza de las ciencias a partir de la perspectiva educacional de Paulo Freire. La propuesta está basada en la obra del autor Extensión o comunicación?. Los elementos apuntados como posibilidades de abordaje contextualizada no son conclusivos, pero, sí, reflexiones que abren caminos para un trabajo contextualizado en la formación de profesores y en la enseñanza de las ciencias, especialmente acerca el rompimiento con una formación pautada en los presupuestos de la racionalidad técnica. En síntesis, se resalta la contribución de la perspectiva freireana en la superación de conceptos extensionistas de enseñanza.

Palabras clave: Formación de profesores. Enseñanza de las ciencias. Perspectiva freireana de educación.

*Universidade Federal
de Santa Catarina (UFSC)
Florianópolis, SC - Brasil
Doutora em Educacãão Científica
e Tecnológica pela Universidade
Federal de Santa Catarina (UFSC).
Professora do Departamento de
Metodologia de Ensino da UFSC.
E-mail:
carolina.sf@ufsc.br
**Universidade Federal
de Santa Catarina (UFSC)
Florianópolis, SC - Brasil
Doutor em Ricerche in Scienze
Chimiche pela Universita degli Studi
di Venezia - Itália. Professor do
Departamento de Metodologia de
Ensino da UFSC. E-mail:
bebeto@ced.ufsc.br
***Universidade Federal
de Santa Catarina (UFSC)
Florianópolis, SC - Brasil
Doutor em Educação pela
Universidade de São Paulo (USP).
Professor do Departamento de
Metodologia de Ensino da UFSC.
E-mail:
demetrio.neto@ufsc.br

DOI - http://dx.doi.org/10.1590/1983-21172016180201

Revista Ensaio| Belo Horizonte | v.18| n. 2 | p.9-28| mai-ago| 2016 
CONTEXTUALIZATION IN INITIAL SCIENCE TEACHERS' TRAINING AND PAULO FREIRE'S EDUCATIONAL PERSPECTIVE

ABSTRACT: This work proposes to support theoretical and methodological reflections on contextualized practice in the initial teacher training and in teaching Science, from Paulo Freire's educational perspective. The proposal builds on the work Extension or Communication?, from the aforementioned author. The elements identified as contextualized approach possibilities are not conclusive, but they are reflections that open paths for a work contextualized in teacher's training and science education, especially about cutting off training guided in technical rationality assumptions. In general, the contribution is that it highlights Freire's perspective in overcoming educational extension conceptions.

Keywords: teachers' training; science teaching; Freire's education perspective. 


\section{CONSIDERACְÕES INICIAIS}

Este estudo pretende favorecer reflexões de ordem teórica e metodológica sobre práticas contextualizadas na formação inicial de professores e no ensino de Ciências a partir de articulações com a perspectiva freireana, em particular, com a obra Extensão ou Comunicação (FREIRE, 1977). Embora a literatura da área e os documentos oficiais destinados à reforma da educação básica como as Diretrizes Curriculares Nacionais do Ensino Médio (DCNEM) e os Parâmetros Curriculares Nacionais para o Ensino Médio (PCNEM) já tenham apontado a importância de um ensino contextualizado, não só na educação básica, mas também nos cursos de formação de professores, ainda parece ser imperativa a discussão de abordagens contextualizadas nesses cursos, que possam minimizar também os problemas no processo de ensino e aprendizagem da educação básica.

O debate acerca da noção de "contextualização" abarca tanto a polissemia que essa noção evoca quanto as concepções de currículo que parametrizam as relações que se estabelecem entre o conhecimento científico e a noção de contextualização adotada por determinada concepção curricular.

Apresentam-se, portanto, reflexões a partir da obra Extensão ou comunicação? (FREIRE, 1977), do educador Paulo Freire, significativas para enfrentar o possível problema da abordagem contextualizada na formação de professores e no ensino de Ciências. Desde 1989, ano em que Freire, como secretário da educação do município de São Paulo, aceitou o desafio de consolidar um processo de formação permanente de professores da rede pública da capital paulista, com o objetivo de promover um ensino contextualizado, tendo como referência uma abordagem temática efetivada através do processo de investigação temática ${ }^{1}$ (FREIRE, 2005; DELIZOICOV, 2008; SILVA, 2013, TORRES; FERRARI; MAESTRELLI, 2014), iniciativas semelhantes vêm ocorrendo (SILVA, 2004; DELIZOICOV, N.; STUANI; DELIZOICOV, D., 2013) em redes públicas de ensino, e em várias regiões do Brasil. Além de Pedagogia do Oprimido (FREIRE, 2005), o livro Extensão ou comunicação? (FREIRE, 1977) tem sido uma das referências básicas para a formação permanente que ocorre nessas redes de ensino, de modo que os educadores atuem na construção curricular parametrizada pela contextualização e pelos temas geradores.

Assim, a escolha dessa obra específica se dá em virtude de seu caráter político-educacional; de sua compreensão gnosiológica acerca da educação; da ênfase da não redução dos processos formativos à aplicação de técnicas; da importância efetiva da comunicação no ato educativo e da aproximação tácita com o ensino de Ciências.

Os aspectos de Extensão ou Comunicação? (FREIRE, 1977) são explorados também como uma possibilidade de levantar elementos que possam auxiliar no processo de difusão e apropriação de conhecimentos científicos tendo como eixo estruturador de currículos a perspectiva da contextualização, conforme tem sido proposto em vários trabalhos, por exemplo, os de Ricardo (2005); Coelho e Marques (2007); Santos (2008). 


\section{A CONTEXTUALIZACÃO NA LITERATURA DE ENSINO DE CIÊNCIAS: APROXIMA- ÇÕES COM A PERSPECTIVA FREIREANA DE EDUCAÇÃO}

Após a divulgação dos documentos oficiais em especial DCNEM e PCNEM da reforma da educação básica, aumentou consideravelmente o número de publicações destinadas a discutir e desenvolver "novas" interpretações acerca da noção de contextualização. A literatura de ensino de Ciências tem contribuído, desde o início dos anos 2000, para essa discussão de forma significativa, sobretudo na sinalização de possibilidades de contextualização à luz da perspectiva freireana de educação.

Nessa direção, Ricardo (2005), por exemplo, aponta a contextualização como indissociável da problematização defendida por Freire (2005). Tal perspectiva aposta no diálogo autêntico entre educadores e educandos com vistas à transformação da realidade via problematização. Para discutir a sua amplitude, Ricardo (2005) levanta outros elementos da obra freireana que remetem à problematização, como a investigação temática. Além disso, aponta que, durante o processo investigativo, as situações-limite ${ }^{2}$ podem ser exploradas. Segundo argumenta Freire (2005), fundamentando-se em Vieira-Pinto (1960), estas têm sua historicidade em sintonia com a perspectiva sócio-histórica da contextualização referente à transformação da realidade que necessita ser acompanhada da práxis ${ }^{3}$.

Coelho e Marques (2007) argumentam a favor de uma abordagem contextualizada via reflexões teórico-metodológicas, ao partirem também do referencial freireano de educação e dos temas químicos sociais (SANTOS; SCHNETZLER, 1997). Para eles, “[...] a contextualização se constitui num instrumento teórico e princípio curricular de fundamental importância para o empreendimento de uma educação que se enquadre na perspectiva transformadora" (COELHO; MARQUES, 2007 p. 10). Os autores creem na possibilidade de desenvolver caminhos metodológicos para que ocorra uma aproximação entre a proposta contextualizada ligada aos temas químicos sociais e a educação transformadora de Paulo Freire. Para isso, indicam o "tema dobradiça" - para Freire (2005), o tema dobradiça não é detectado na investigação temática como um tema gerador, embora seja considerado um tema importante para uma determinada comunidade e que articula diferentes conhecimentos como elemento de aproximação com os "temas químicos sociais". Em outras palavras, a ideia é partir de um tema escolhido pela comunidade de professores de Química - "tema químico social" - e edificá-lo como um "tema dobradiça", o que possibilitaria uma abordagem da contextualização por meio dos temas químicos sociais e uma aproximação com a perspectiva educacional defendida por Freire (COELHO; MARQUES, 2007).

Dessa forma, na aproximação dos temas químicos sociais à perspectiva freireana de tema dobradiça, torna-se imprescindível e necessário que os professores estejam aptos a desvelar as situações significativas presentes na comunidade, conforme destacam Coelho e Marques (2007), o que implica obter dados referentes à manifestação dessas situações para problematizá-los, bem como problematizar a interpretação desses dados por parte dos alunos e dos professores em processos de formação continuada. 
Uma possível forma de favorecer abordagens contextualizadas pode ser a articulação da perspectiva educacional de Freire ao enfoque CTS (Ciência, Tecnologia e Sociedade). Conforme argumenta Freire (2005), a educação não pode ser um processo neutro de alienação dos sujeitos, o enfoque CTS também enfatiza que os processos científicos e tecnológicos não são autônomos, desmistificando o suposto determinismo e a neutralidade científica e tecnológica. Portanto, um dos pontos de convergência entre o enfoque CTS e a perspectiva freireana de educação é a valorização da participação da sociedade na tomada de decisões democráticas (AULER; DELIZOICOV, 2006), constituindo-se também em uma forma dialógica.

Como argumenta Auler (2003), a abordagem CTS enfatiza a necessidade de colocar em prática a tomada de decisões mais democráticas em detrimento das tecnocráticas ${ }^{5}$, mas para que isso ocorra é necessário superar o que Freire (2005) denominou de "cultura do silêncio", caracterizada pela ausência da população em processos decisórios. Ao mesmo tempo, Auler (2003) salienta a vocação ontológica da obra freireana, a saber: o ser humano como sujeito histórico e não objeto.

Tem-se, então, como um dos argumentos de aproximação entre o enfoque CTS e a perspectiva freireana de educação, justamente o processo de tomada de decisões democráticas. Salienta-se também a importância no âmbito escolar de atividades que explorem a capacidade reflexiva dos estudantes a fim de que os conhecimentos científicos aprendidos auxiliem na compreensão da realidade com vistas a transformá-la.

Santos (2008), ao articular o enfoque CTS e a perspectiva humanística freireana, busca problematizar a questão do uso ou não de aparatos tecnológicos, além de propor uma educação capaz de refletir acerca das condições existenciais dos educandos. Argumenta também que é preciso levar em conta as condições de opressão em que os sujeitos vivem. A abordagem temática, na perspectiva dos temas sociais e na freireana, é entendida por Santos (2007) como possibilidade de abordagens contextualizadas.

As ideias apresentadas constituem exemplos de propostas contextualizadas que exploram aspectos da proposta freireana de educação, as quais podem ser abordadas em processos formativos. Na sequência, levantam-se possíveis reflexões de um processo de formação de professores contextualizado a partir da obra Extensão ou Comunicação? (FREIRE, 1977).

\section{A CONTEXTUALIZACฺÃO NA FORMAC̣̃̃O DE PROFESSORES E NO ENSINO DE CIÊN- CIA À LUZ DA OBRA EXTENSÃO OU COMUNICAÇÃO?}

Na obra, Freire (1977) explora o problema da "comunicação" entre o agrônomo e o camponês no processo de reforma agrária, destacando, sobretudo, a importância do papel da formação tanto do camponês, como educando no processo de apropriação das técnicas agrícolas, quanto do agrônomo, no papel de educador. Ou seja, a formação problematizada por Freire propõe alterar a relação entre ambos. De modo semelhante, afirma-se que a formação inicial, dependendo de como se desenvolva, pouco pode influir na forma como se estabelecem, hegemonicamente, as relações entre professores e estudantes. Portanto, é preciso 
que se considere, desde a formação inicial à contextualização, não apenas dos conteúdos conceituais relacionados ao tema, mas também os conteúdos relacionados especificamente à docência.

A relação entre a conceituação específica e seu respectivo ensino na universidade exige o domínio, por parte do docente universitário, dessa conceituação e da estrutura que lhe dá significado, embora não se resuma apenas a esse domínio cognitivo.

Há outra dimensão integrante da docência na graduação que se refere ao próprio ato de ensinar essa conceituação. A atuação docente na graduação tem sido objeto de estudo e análise em alguns trabalhos, conforme salienta Bazzo (2007), uma vez que a formação desse professor é marcada, fundamentalmente, por um processo voltado para a profissionalização de um pesquisador. Trata-se, portanto, de examinar o que ocorre com um pesquisador que, concomitantemente a suas atividades de pesquisa, precisa se dedicar ao ensino de disciplinas de cursos de graduação, e por vezes, de pós-graduação.

Uma compreensão de como o docente com esse perfil de formação tem se constituído como um profissional, o qual, além de pesquisador atua também como professor em disciplinas específicas da área de C\&T, ainda está tomando forma, conforme assinalam Oda (2012) e Oda e Delizoicov (2011). Os autores destacam que, embora haja certa tradição de pesquisa com foco na docência universitária, esta é, particularmente, incipiente quando se trata de professores do Ensino Superior que lecionam em disciplinas específicas dos cursos das áreas das ciências da natureza, tais como os que formam licenciados em Biologia, Física e Química.

Contudo, há exemplos que contribuem para se entender o desafio enfrentado por pesquisadores que se tornam professores de disciplinas específicas oferecidas para alunos de graduação. Além do estudo acima, cujos autores se detiveram a examinar a atuação de docentes universitários em disciplinas da área de Microbiologia e Parasitologia, destacam-se também o de Gonçalves, Marques e Delizoicov (2007), que analisaram as práticas efetivadas por pesquisadores que lecionam disciplinas de Química básica em cursos de graduação, e de Cortela e Nardi (2004), que abordaram a influência das práticas educativas de formadores de professores de Física na implementação de novos currículos.

No âmbito da educação básica, Halmenschlager (2014) sinaliza que os professores demostram preocupação em organizar práticas que estabeleçam algum nível de articulação entre conceituação científica e situações contextuais. Dessa forma, há um empenho por parte dos docentes, no contexto investigado, na apreensão e na discussão de dados relativos à vivência dos alunos. Isto é, há uma preocupação desses professores com um ensino contextualizado.

Em Extensão ou Comunicação?, Freire (2007) discute amplamente os conceitos de "doxa" e "logos". Para ele, a "doxa" é análoga a uma percepção mágica da realidade, relacionada com o que, usualmente, denomina-se de senso comum. $\mathrm{O}$ "logos" equivale a um conhecimento fundamentado sobre a realidade, sobretudo, de conhecimentos sistematizados. Nas práticas educacionais, a "doxa" não está associada apenas à concepção dos estudantes ${ }^{7}$ em torno dos conteúdos estudados, uma vez que os professores, tanto do nível superior quanto da educação básica, também podem possuir sua "doxa" a respeito da realidade e no que concerne à própria profissão. 
Entretanto, com base em uma visão freireana, a interação do professor com os estudantes não pode ocorrer no nível da "doxa" daquele. Os educadores têm, além de sua "doxa" em assuntos alheios à própria especialidade, um "logos" capaz de interagir com a "doxa" dos estudantes. E esse "logos", advindo de sua especialização, não pode ser meramente verbalizado aos estudantes, conforme argumenta Freire (1977), pois é preciso "problematizar" a "doxa" dos educandos com base no "logos" do professor. Em se tratando do professor que atua em disciplinas específicas dos cursos de licenciatura, sua "doxa", se e quando necessário, comportaria também uma problematização de sua práxis educativa em disciplinas que ministra nos cursos de graduação. Conforme se destacou, a formação profissional desse docente universitário e, portanto, de seu "logos", é, fundamentalmente, a de um pesquisador em sua área de atuação. A iniciativa recente da obrigatoriedade da realização do Estágio de Docência por bolsistas da CAPES (Coordenação de Aperfeiçoamento de Pessoal de Nível Superior) dos cursos de pós-graduação indica a intenção de se introduzir também, na formação de pesquisadores, a dimensão relativa ao ensino em disciplinas da graduação como um dos aspectos formativos. Será necessário, contudo, um estudo sobre o impacto dessa iniciativa na formação de futuros professores da educação superior.

Em contrapartida, na visão de Freire (1977), o educador não tem o direito de impor suas ideias aos educandos, mas sim, a "obrigação" de discutir a respeito do "logos". Quando se valoriza um conhecimento em detrimento de outro, por exemplo, o conhecimento científico, no caso da educação básica, a intenção é a de possibilitar que esses sujeitos, que estão em processo de formação, possam emergir da "doxa" para o "logos". A superação da "doxa" se faz necessária no sentido da ação educativa ser verdadeiramente uma situação gnosiológica. Como expõe o autor:

Ao contrário, educar e educar-se, na prática da liberdade é uma tarefa daqueles que sabem que pouco sabem - por isso sabem que sabem algo e podem assim chegar a saber mais - em diálogo com aqueles que, quase sempre, pensam que nada sabem, para que estes transformando o seu pensar que nada sabem em saber que pouco sabem, possam igualmente saber mais (FREIRE, 1977, p. 25).

Nessa direção, Freire argumenta em favor do rigor científico nas práticas educacionais como sendo uma possibilidade de superação da "doxa". Salientase também que o rigor científico defendido não deve ser interpretado como reducionismo científico, isto é, a redução do trabalho educacional parametrizado por conteúdos conceituais oriundos do corpo de conhecimentos produzidos pelas ciências da natureza, tais como as teorias da Biologia, da Física e da Química. Mesmo que esses conteúdos necessitem compor os currículos e programas escolares, a sua disseminação em processos educativos implica em um "logos" contido em conhecimentos oriundos de outras áreas. A rigorosidade se faz imperativa para uma educação problematizadora, como destacam Freire e Shor (2003, p. 14): "O rigor é um desejo de saber, uma busca de resposta, um método crítico de aprender. Talvez o rigor seja, também uma forma de comunicação que provoca o outro a participar, ou inclui o outro numa busca ativa". Essa rigorosidade científica precisa estar presente na formação de professores, de forma geral, a fim de superar 
concepções simplistas a respeito do que é ser professor.

A superação da "doxa" pelo "logos" pode ser buscada através do diálogo problematizador em que o conhecimento, seja técnico, científico ou educacional, tenha relação indissociável com a realidade em questão (FREIRE, 1977). Isto é, explorar categorias freireanas como "dialogicidade" e "problematização" pode constituir possibilidades de compreensão e transformação da realidade. Para Freire, parece existir uma relação bastante intensa entre a compreensão da realidade e sua transformação", pois a própria compreensão já demanda uma investigação acerca da realidade.

A transformação da realidade também pode ser favorecida pela compreensão dos conhecimentos científicos e sua indissociável relação com os condicionamentos históricos. Isso significa que os conhecimentos são carregados de relações de permanência e mudança ao longo da continuidade histórica. Como destaca Freire: "Somente a ingenuidade tecnicista pode crer que, decretada a reforma agrária e posta em prática, tudo o que antes foi já não será; que ela é um marco decisório e rígido entre a velha e a nova mentalidade" (FREIRE, 1977, p. 62).

Um exemplo do velho no novo são as reformas curriculares nacionais. Esses documentos representam avanços significativos nas formas de se compreender o processo de ensino e aprendizagem. No entanto, sua "imposição" não garante um olhar transformador para o ensino por parte de seus leitores. Nesse sentido, salienta-se, em especial, o lançamento dos PCNEM (BRASIL, 1999), os quais não se caracterizaram ainda como divisores de águas entre o ensino "tradicional" e o contextualizado, embora seja possível perceber avanços entre os professores em relação à apropriação curricular, conforme destaca Leal (2003).

Assim sendo, Freire, ao analisar um processo educativo que ocorrera no Chile durante a sua estadia naquele país, argumenta que o trabalho do educador não pode limitar-se à substituição dos conhecimentos empíricos dos camponeses pelos seus conhecimentos técnicos, pois é improvável a substituição de um conhecimento por outro sem que isso repercuta em outras dimensões da "existência dos homens", além de ser impossível a existência de um processo educativo neutro (FREIRE, 1977).

Um trabalho pautado na "dialogicidade" e na "problematização" dos conhecimentos científicos considera que é preciso romper com a forma extensionista de educação, inclusive aquela que, muitas vezes, caracteriza os processos de formação continuada de professores. Em sua obra, Freire aprofunda a análise acerca da necessidade de se romper com a concepção de extensão que pressupõe apenas uma via de informação, isto é, aquela que se origina no especialista para o não especialista. Ele argumenta sobre a necessidade de se implementar a dimensão dialógica para possibilitar a apreensão e compreensão da percepção do não-especialista sobre os problemas enfrentados e para que essa percepção possa ser problematizada de tal modo que, durante o processo educativo, seja planejada a inserção dos conhecimentos dos especialistas como uma contribuição na busca de soluções para a problematização que se realiza. Freire se aprofunda, particularmente, na "extensão" ocorrida de técnicas agrícolas dos agrônomos aos camponeses, ao destacar que esse tipo de ação "extensionista” pode se caracterizar como uma forma de alienação dos sujeitos em formação, uma vez que pode ocorrer simplesmente a substituição de práticas agrícolas, sem que haja, contudo, 
uma problematização que possibilite a apropriação de uma nova prática como resposta para um problema que práticas anteriores não solucionaram.

O que Freire propõe, com o processo dialógico e problematizador, é que a apropriação do novo ocorra de modo planejado na ação educativa: de um lado, o diálogo possibilitaria a identificação de problemas relativos às significações significativas, contidas nas manifestações locais das contradições, e a compreensão que o educando estaria tendo dos problemas; de outro, a busca problematizada de soluções para esses problemas. É por causa dessas características que Freire concebe a "educação como uma situação gnosiológica", conforme intitula, inclusive, um dos subcapítulos de Extensão ou Comunicação? (FREIRE, 1977, p. 74). Nessa dinâmica é fundamental um planejamento escolar mediado por situações significativas e pelos problemas nela envolvidos, de modo a problematizar uma "doxa" que, eventualmente, esteja obstruindo a compreensão dos problemas e planejar a abordagem de outras compreensões, oriunda de um "logos" que pode, de alguma forma, contribuir para solucionar esses problemas. Evidentemente, trata-se de um processo formativo cuja intenção tem como horizonte o porvir, e não necessariamente, a ação imediata no âmbito da educação escolar. Trata-se de uma compreensão parametrizada pela dimensão histórica concebida por Freire sobre o processo de humanização.

De modo semelhante, faz-se necessário romper com a "extensão" dos conhecimentos dos professores para os estudantes, tanto na educação básica quanto na educação superior, em particular na formação inicial de professores. Nessa compreensão, parece fundamental que os problemas relativos ao contexto em que os professores das escolas básicas atuam precisam mediar igualmente, através de ações planejadas, o processo formativo, não só o inicial, em cursos de licenciatura, mas também o continuado.

Destaca-se, portanto, que a compreensão de Freire sobre o termo "extensão" comporta um sentido segundo o qual quem estende, estende alguma coisa até alguém. "Daí que, em seu 'campo associativo' o termo extensão se encontre em relação significativa com transmissão, entrega, doação, messianismo, mecanicismo, invasão cultural, manipulação" (FREIRE, 1977 p. 22).

O trabalho de um educador extensionista, conforme a crítica de Freire (1977) quanto a algumas das práticas ocorridas no Chile, constituiu-se em estender seus conhecimentos até os educandos. Essa tentativa de extensão do conhecimento de um sujeito a outro pode estabelecer relacionamentos de opressão, ou seja, na ação extensionista existe um sujeito que persuade - neste caso, o educador extensionista - e outro em que a ação da persuasão recai - o educando (FREIRE, 1977). Nessa ótica, há um sujeito da ação, que estende o "conhecimento", e outro que recebe o "conhecimento", sendo este, portanto, o objeto da ação. Freire resume nessas palavras o equívoco de entender os sujeitos como objetos: "Conhecer é tarefa de sujeitos, e não de objetos. E é como sujeito e somente enquanto sujeito, que o homem pode realmente conhecer" (FREIRE, 1977, p. 27). Essa interação entre sujeito cognoscente e o objeto do conhecimento é uma relação não neutra.

Logo, a ação extensionista, segundo Freire, não corresponderia à educação verdadeiramente libertadora e gnosiológica, por ele defendida e que aposta nas relações entre os sujeitos mediados pelo objeto de estudo e não pela transformação 
do sujeito em objeto. A gênese do conhecimento, para Freire, não está só no sujeito ou só no objeto, mas na interação entre ambos, mediada por processos históricos e culturais no enfrentamento de problemas. A educação pautada na extensão "nega os sujeitos como seres da transformação do mundo” (FREIRE, 1977, p. 22), reduzindo-os a seres de reprodução dos modelos vigentes e transformando-os, em seguida, em seres da adaptação ${ }^{10}$.

$\mathrm{O}$ investimento em uma formação inicial de professores pautada nos pressupostos da dialogicidade não pode estar "engessado" ao cumprimento de uma lista de conteúdos específicos, pois, ainda que esta tenha importância na organização do trabalho docente, é apenas um dos eixos diretores que necessitam ser planejados durante a ação docente. Freire (1977, p. 86) argumenta que "não é possível ensinar técnicas sem problematizar toda a estrutura em que se darão as técnicas”.

A forma extensionista de educação também se assemelha aos pressupostos da racionalidade técnica, que reduz os educandos a meros receptores de conteúdos programáticos, da mesma forma que reduz o trabalho docente à aplicação de técnicas. A respeito disso, Freire (1977, p. 24) afirma que, quando o educador "se recusa à 'domesticação' dos homens, sua tarefa corresponde ao conceito de comunicação e não ao de extensão”. Nessa direção, expõe as implicações do desenvolvimento tecnológico para o trabalhador rural e como o agrônomo não extensionista precisa interagir com o conhecimento daquele:

O agrônomo não pode, em termos concretos, reduzir o seu quefazer a esta neutralidade inexistente: a do técnico que estivesse isolado do universo mais amplo em que se encontra como homem $[\ldots]$.

Daí que tais proposições, para falar só neste aspecto, tanto possam defender ou negar a presença participante dos camponeses como reais co-responsáveis pelo processo de mudança. Como também possam inclinar-se pelas soluções tecnicistas ou mecanicistas que, aplicadas ao domínio do humano, como, indubitavelmente, o é o domínio em que se verifica a reforma agrária, significam fracassos objetivos ou êxitos aparentes (FREIRE, 1977, p. 56).

Neste contexto, o autor critica tacitamente visões salvacionistas ${ }^{11}$ em relação ao desenvolvimento científico e tecnológico, especialmente por entender que a simples inserção de técnicas agrícolas não modificará a percepção dos camponeses a respeito da realidade. A crítica feita por Freire (1977) a essa visão não desconsidera os benefícios advindos dos conhecimentos científicos e tecnológicos. Além disso, salienta que existe um posicionamento político no processo de reforma agrária. De modo semelhante, considerando a não neutralidade dos processos educativos, há também um posicionamento político, presente nos cursos de formação de professores, que evidencia posições ideológicas dos formadores, sejam estas antidialógicas ou dialógicas. Com base no exposto, o autor argumenta:

A reforma agrária deve ser um processo de desenvolvimento do qual resulte necessariamente a modernização dos campos, com a modernização da agricultura.

Se tal é a concepção que temos da reforma agrária, a modernização que dela resulte não será fruto de uma passagem mecânica do velho até ela, o que, no fundo, não chegaria a ser propriamente uma passagem, porque seria a superposição do novo no velho. Numa concepção não mecanicista, o novo nasce do velho através da transposição criadora que se 
verifica entre a tecnologia avançada e as técnicas empíricas dos camponeses.

Isto significa, então, que não é possível desconhecer o back-ground cultural que explica os procedimentos técnico-empíricos dos camponeses. Sobre esta base cultural - em que se constituem suas formas de proceder, sua percepção da realidade - devem trabalhar todos os que tenham esta ou aquela responsabilidade no processo de reforma agrária (FREIRE, 1977, p. 57-58).

O trabalho do agrônomo educador, nesse contexto, precisa considerar os conhecimentos iniciais dos camponeses e problematizá-los com o objetivo de se alcançar uma nova percepção a respeito da realidade. Esse trabalho de entender o que os camponeses pensam e de buscar formas "dialógicas" de apropriação do novo conhecimento caminha ao encontro do que Freire (1977) denominou de "comunicação". É em vista da implementação dessa compreensão dialógica e comunicativa que convém considerar que há professores, nos diferentes níveis de ensino, cujas práticas docentes precisam ser problematizadas para que possam atuar em uma perspectiva contextualizada, segundo a concepção caracterizada neste trabalho.

Nesse sentido, quando se analisam aspectos educativos que implicam em transformações, existe uma relação entre a formação de professores e a situação exemplificada por Freire acerca do processo de reforma agrária. Um exemplo disso é o caso dos documentos destinados à reforma da educação básica, por exemplo, os PCN, que não vêm proporcionando um trabalho contextualizado, sobretudo no que tange a uma visão mais crítica em superar concepções de contextualização como, por exemplo: ilustração de conteúdos conceituais com fatos do dia a dia; inserção de novas tecnologias de informação e comunicação, sem que os professores tenham se apropriado criticamente dessas ferramentas para explorá-las nas aulas; introdução de aspectos do cotidiano nas aulas com a simples finalidade de minimizar um trabalho puramente conceitual; abordagem do cotidiano e distanciamento em relação ao conhecimento científico; e a simples descrição de aspectos da realidade dos estudantes sem um devido aprofundamento.

De modo semelhante, a formação de professores necessita extrapolar práticas pedagógicas baseadas na mera exposição e aplicação de conteúdos conceituais a fim de superar os pressupostos extensionistas, isto é, há a necessidade de se superar a dicotomia entre o conhecimento técnico/conceitual e o cultural (FREIRE, 1977), considerando que o que está em jogo são transformações em práticas culturais para a compreensão de problemas que necessitam de soluções.

Dessa forma, a comunicação corresponde a uma prática educacional reflexiva que tem compromisso com a ação e com seu planejamento nas atividades a serem desenvolvidas. A qualidade dessa ação, assim como seu planejamento, implica negar a redução da comunicação a meros comunicados de um sujeito a outro, conforme é a proposição de Freire (2005) para a efetivação da Investigação Temática. Além disso, o ato de comunicação não se consolida se alguma das partes envolvidas não compreender o significado dos conhecimentos estudados. Ou seja, no ato comunicativo não existem sujeitos ativos e outros passivos, pois todos são igualmente sujeitos da ação e da reflexão, constituindo-se em sujeitos da práxis, haja vista a necessidade de o professor apreender e problematizar o conhecimento do qual o estudante já é portador para poder planejar sua ação docente. 
Assim, o trabalho educacional contextualizado, oriundo do processo de investigação temática, não pode constituir-se apenas em comunicados a respeito de conhecimentos científicos e tecnológicos, e sim, precisa estar imerso na dimensão da comunicação proposta por Freire:

O sujeito pensante não pode pensar sozinho; não pode pensar sem a coparticipação de outros sujeitos no ato de pensar sobre o objeto. Não há um "penso", mas um pensamos. É o "pensamos" que estabelece o "penso" e não o contrário.

Esta co-participação dos sujeitos no ato de pensar se dá na comunicação. O objeto, por isto mesmo, não é a incidência terminativa do pensamento de um sujeito, mas o mediador da comunicação (FREIRE, 1977, p. 66).

O sujeito ontológico de Freire se caracteriza por ser histórico, produtor de cultura, e por isso, um sujeito que se constitui na comunicação com os outros e nas relações com a natureza, e não na extensão. A comunicação implica relações de reciprocidade entre os sujeitos envolvidos, ou seja, a comunicação é dialógica. O autor afirma ainda que: "A educação é comunicação, é diálogo, na medida em que não há transferência de saber, mas um encontro de sujeitos interlocutores que buscam a significação dos significados" (FREIRE, 1977, p. 69).

No entanto, para que ocorra uma relação dialógico-comunicativa, os sujeitos envolvidos precisam expressar-se através de um mesmo sistema de signos linguísticos (FREIRE, 1977). A comunicação verbal, por exemplo, utilizada por um dos sujeitos, necessita ser entendida pelos demais, e, caso não haja um entendimento em torno desses mesmos signos, a comunicação pode ser impedida. Para Freire, a inteligibilidade e a comunicação ocorrem simultaneamente. Quando se trata de formação de professores, particularmente nos cursos de licenciatura, uma dinâmica que envolve contextualização permite que situações que necessitam de conceituação científica para a sua compreensão, ainda não apropriada pelos licenciandos, sejam introduzidas através de um processo tal qual explorado por Freire com seu conceito de comunicação. Trata-se de propiciar uma compreensão da "nova" linguagem, implicada na conceituação científica, mediada pela situação contextualizada, ao invés de sua "incorporação" mecânica. A intenção é que essa prática docente do formador, ao se tornar exemplar, possa contribuir para a atuação profissional do professor em formação.

As convicções mágicas pelas quais os camponeses entendem a realidade precisam ser problematizadas pelos agrônomos dentro de um domínio de significados para os primeiros. Esses significados não podem se dar na substituição do conhecimento empírico dos camponeses pelo conhecimento técnico dos agrônomos. É fundamental compreender não só o significado dos signos linguísticos dos camponeses, mas também a compreensão do contexto em que esses sujeitos construíram tais significados. De modo semelhante, no processo de formação docente, o desafio a ser enfrentado é o da compreensão dos significados presentes nos conhecimentos dos alunos e de seus formadores, sejam aqueles relacionados à conceituação científica, sejam os empíricos, oriundos de práticas educacionais históricas, mas que, todavia, não contemplam, por exemplo, alguma compreensão de ensino contextualizado. Para Freire (1977 p. 82), “esta inteligibilidade dos signos vai-se dando na dialogicidade que, desta forma, possibilita a compreensão 
exata dos termos, através dos quais os sujeitos vão expressando a análise crítica do problema, em que se acham empenhados".

A comunicação entre técnicos e camponeses, e igualmente em cursos de formação de professores, deve basear-se no "logos" e não na "doxa", nem de uns nem de outros. A rigorosidade científica deve estabelecer-se a partir de um diálogo efetivo que gere nos sujeitos envolvidos a necessidade de apropriação de um novo conhecimento, seja de cunho científico, seja de cunho educacional.

Nessas condições, a comunicação rejeita qualquer forma de adaptação dos seres no mundo e encara a realidade como algo inacabado, suscetível, sobretudo, a transformações culturais advindas do desenvolvimento científico e tecnológico, além do educacional, que parametriza a apropriação dos conhecimentos em C\&T. Por conseguinte, Ciência e Tecnologia constituem-se como causa e efeito de transformações culturais na continuidade da história, assim como ocorreu com a escrita alfabética, por exemplo.

Essas transformações culturais podem ser mais bem-entendidas na indissociável relação ser humano/mundo, em que ambos, inacabados, se encontram em uma permanente relação em que o sujeito transforma o mundo e sofre, igualmente, os efeitos dessa transformação. Logo, a educação não pode compreender os sujeitos isolados do mundo, tampouco o mundo sem os sujeitos. Isso ocorre em razão de a educação ser histórica, isto é, a história é feita pelos sujeitos ao passo que eles se fazem ao longo da história, constituindo ser humano e mundo como inacabados e transformáveis (FREIRE, 1977). Portanto, a problematização centra-se nas relações ser humano-mundo e não no ser humano isolado do mundo.

No entanto, para que ocorra a compreensão de sujeito e mundo como transformáveis, são necessárias mudanças nos níveis de consciência dos sujeitos envolvidos nos processos de ensino e aprendizagem, conforme argumenta Freire (1977; 2005). Uma das primeiras mudanças é a superação da dimensão individual, pois a tomada de consciência não se dá nos sujeitos de forma isolada. Freire, assim, discorre acerca da conscientização:

Se a tomada de consciência, ultrapassando a mera apreensão da presença do fato, o coloca, de forma crítica, num sistema de relações, dentro da totalidade em que se deu, é que, superando-se a si mesma, aprofundando-se, se tornou conscientização.

Este esforço da tomada de consciência em superar-se a alcançar o nível da conscientização, que exige sempre a inserção crítica de alguém na realidade que se lhe começa a desvelar, não pode ser, repitamos, de caráter individual, mas sim social (FREIRE, 1977, p. 77).

Portanto, a conscientização, nessa compreensão, está associada a processos que se relacionam com estruturas sociais e com as interações que ocorrem nelas, e não na esfera individual, ressaltando, assim, o caráter coletivo do sujeito para Freire. Cabe destacar, no entanto, que a valorização do trabalho coletivo não exclui as individualidades que ocorrem no processo de ensino e aprendizagem, pois, é na própria interação de cada indivíduo com seu meio físico e social que ele se humaniza e se constitui como um sujeito que tem sua historicidade, na compreensão do educador.

O processo de conscientização, ao negar a domesticação, empenha-se na tentativa de compreender e transformar a realidade. A educação como prática da 
liberdade não se sujeita à transmissão de conteúdos escolares inertes, simplesmente elencados nos programas de ensino a serem cumpridos. Ao contrário, nega o depósito de conteúdos e a ideia de cultura como algo intocável (FREIRE, 1977). Pretende-se que o processo educativo tenha uma matriz problematizadora, que possa caracterizar a gênese de conhecimentos, mesmo aqueles que já tenham sido produzidos historicamente. Estes, como conteúdos programáticos escolares, e ainda "novos" para os alunos, terão a alternativa de serem apropriados por eles como respostas às perguntas que se relacionam com as situações contraditórias acerca de seu contexto físico e sociocultural.

Perguntas com essas características invocam situações novas e novos caminhos para acessar o objeto de estudo. Esse (re)fazer exige a apropriação do conhecimento científico, que se dá no nível do "logos", no constante problematizar da "doxa", para que possa constituir-se em uma verdadeira situação gnosiológica, desafiando os sujeitos envolvidos no processo educativo a pensar criticamente (FREIRE, 1977).

Nessas condições, para Freire, a educaçãoé “duração”, pois não se caracteriza só pela permanência ou só pela mudança: dura na contradição entre a permanênciamudança. A educação é permanente no sentido de duração, a permanência não no sentido de valores permanentes, mas de permanência do processo educativo. A mudança se constitui em relação aos condicionamentos históricos e sociais da educação, e à medida que dura, também se transforma, convertendo-se em força de transformação, ou seja, o autor compreende a educação como transformação da realidade (FREIRE, 1977). Assim, “a educação que não se transformasse ao ritmo da realidade não 'duraria', porque não estaria sendo" (FREIRE, 1977, p. 84). Por conseguinte, segundo Freire, é “assim é que vemos o trabalho do agrônomoeducador. Trabalho no qual deve buscar em diálogo com os camponeses, conhecer a realidade, para com eles, melhor transformá-la" (FREIRE, 1977, p. 85).

Tendo como pressuposto a educação como uma situação gnosiológica, Freire (1977, p. 86) indaga: "quando começa a relação com o objeto cognoscível? E como organizar o conteúdo programático dessa educação?”. Para ele, o ponto de partida do diálogo entre professores e estudantes encontra-se na busca pelo conteúdo programático. Por essa razão, os conteúdos são selecionados no processo de Investigação Temática que se caracteriza, fundamentalmente, pela busca das manifestações locais de contradições mais amplas e pela compreensão que estudantes e professores mantêm delas. E é a partir do conhecimento dos estudantes que se poderá problematizá-lo como um conteúdo manifestado por sua "doxa", e em seguida, planejar a abordagem problematizadora de outro conteúdo programático referenciado pelo "logos" de especialistas, durante a redução temática por eles organizada (FREIRE, 1977, 2005). Isto é, o diálogo com os educandos não se inicia apenas no âmbito da sala de aula, mas sim, na organização e na escolha dos conteúdos programáticos, entre os quais estão aqueles que devem ser selecionados de estruturas conceituais contidas nas teorias e nos modelos científicos.

Na construção do conteúdo programático é essencial a presença do coletivo, mas um coletivo formado não apenas por professores, já que a participação do estudante também se faz necessária nesse contexto, como argumenta Freire (1977):

No caso do agrônomo, se ele elabora, mesmo em equipe, o programa de assistência técnica sem a percepção crítica de como os camponeses percebem a sua realidade - não importa, 
inclusive, que esteja a par dos problemas mais urgentes da área - sua tendência é incorrer na invasão cultural [...] (FREIRE, 1977, p. 87).

A ideia da participação dos camponeses, assim como a da participação dos alunos através de processos educativos escolares, pode ser planejada a partir de uma construção do programa curricular em que o diálogo efetivo com o educando na apreensão das problemáticas da comunidade em que estes estão inseridos possam ser contemplados. O planejamento dessa construção curricular é possibilitado por meio do processo de investigação temática no qual fundamenta-se a compreensão de contextualização na perspectiva freireana.

Uma das formas de se captarem os temas-problemas para os estudantes é através da investigação temática, quando ocorre a pesquisa do tema gerador que caracteriza a educação como uma situação gnosiológica (FREIRE, 2005). A apresentação da temática-problema para os estudantes e o diálogo entre o educador e o educando sobre o tema possibilita o surgimento de outros (FREIRE, 1977). Portanto, a problemática local é ponto de partida para a estruturação do programa curricular, em que a conceituação científica tem seu papel, o que caracteriza a necessidade de articulações local-global, parte-todo, na superação de "doxas" por "logos".

Nas atividades diárias de sala de aula a contextualização pode também ser favorecida através dos três momentos pedagógicos (DELIZOICOV; ANGOTTI; PERNANBUCO, 2002), os quais têm como propósito estabelecer um diálogo problematizador entre o professor e os estudantes, momento em que o conhecimento inicial destes é captado. A intenção de apreender esse conhecimento se dá com a finalidade de problematizá-lo, no intuito de apontar contradições e limitações iniciais quando defrontado com o conhecimento científico (DELIZOICOV; ANGOTTI; PERNANBUCO, 2002). No primeiro momento, denominado "problematização inicial”, apresentam-se situações reais que os estudantes já conhecem e que estão relacionadas com o tema estudado, para logo desafiá-los a expor o que pensam acerca dessas situações. No segundo momento, "organização do conhecimento", são selecionados e sistematicamente estudados conhecimentos necessários para a compreensão dos temas e da problematização inicial. Por fim, no terceiro momento, "aplicação do conhecimento", aborda-se, de forma sistemática, os conhecimentos apropriados (DELIZOICOV; ANGOTTT; PERNANBUCO, 2002).

München e Delizoicov (2014), ao resgatarem o histórico da gênese dessa abordagem através dos três momentos pedagógicos, explicitam alguns parâmetros que, estando presentes em práticas educativas realizadas em sala de aula, podem contribuir com uma perspectiva problematizadora e contextual. Essa perspectiva está alicerçada na potencialidade do conhecimento científico de auxiliar na transformação da realidade, a esse respeito, Ricardo (2005) argumenta que a contextualização dos saberes escolares se constitui na problematização da relação entre o conhecimento científico e o mundo.

Contudo, Munchen e Delizoicov (2014) alertam que o uso desses três momentos, se planejados como uma estratégia de ensino que objetiva introduzir conceituação científica no segundo momento, mas sem considerar situações significativas presenciadas por alunos e problematizadas no primeiro momento, com dados dos locais onde vivem, pode se distanciar de uma dinâmica que se organiza para problematizar a "doxa" presente na compreensão dos alunos sobre o seu contexto. 
Em suma, é possível salientar, na obra freireana, dois aspectos fundamentais para um trabalho educacional contextualizado: o primeiro relaciona-se com o olhar ontológico do autor em compreender os seres humanos como sujeitos da história e não objetos; o segundo diz respeito ao olhar epistemológico preocupado em "desvelar a realidade" dos sujeitos. Portanto, por meio das relações com o mundo, os sujeitos se humanizam.

Freire, na amplitude de suas obras, emprega os termos "humanização" e "libertação" no sentido de melhor compreender as contradições sociais em que os sujeitos estão inseridos, sinalizando a educação - e não somente ela - como um caminho para a transformação da realidade e para alcançar a "humanização" e a "libertação", direitos dos sujeitos. Portanto, consideram-se os elementos aqui apresentados a partir do livro Extensão ou Comunicação?(FREIRE, 1977) como possibilidades plausíveis de abordagens educacionais contextualizadas pautadas nos pressupostos da comunicação, em especial, na formação de professores.

\section{CONSIDERAÇÕES FINAIS}

Em síntese, entendemos que a perceptiva educacional de Paulo Freire pode ter um papel importante na construção de estruturas curriculares, tanto na educação básica quanto na educação superior, que levem em consideração também situações vividas pelos sujeitos em formação e a atuação de seus formadores e que contribuam significativamente para a superação de concepções reducionistas de educação pautadas especialmente em formas extensionistas de ensino. Isto é, uma educação libertadora necessita romper com aquelas formas de ensino puramente "conteudistas", atreladas à concepção de educação tradicional, de um ensino baseado unicamente na transmissão de conceituação específica oriunda de teorias e modelos científicos. Do mesmo modo, é importante ressaltar que a contextualização não se efetiva no vácuo conceitual, havendo a necessidade, assim, de se elaborar um planejamento em que contexto e conceito tenham uma relação não dicotômica. E preciso superar igualmente a concepção de contexto como algo que justifique a inserção de determinada conceituação já selecionada em programas de ensino por critérios, muitas vezes, inerciais.

Por outro lado, se reconhecem dificuldades de implementação da proposta freireana no ensino formal, como por exemplo: as condições para a formação permanente de professores para que estes possam atuar de forma mais problematizadora e contextualizada; a necessidade de uma nova organização funcional da escola que implica no apoio explícito dos órgãos governamentais responsáveis pela educação; o trabalho colaborativo entre formação inicial e formação contínua dos professores da educação básica (DELIZOICOV, 2008). A proposta defendida por Freire $(1997,2005)$ exige um trabalho coletivo de uma equipe interdisciplinar voltada à investigação e à transformação da realidade, aspectos que envolvem um processo de formação permanente de professores que encontra dificuldades, conforme mencionado, mas com potencial formativo profícuo.

Por fim, salienta-se que um trabalho educacional na perspectiva freireana precisa ser discutido e planejado no coletivo de forma a minimizar os efeitos da 
fragmentação excessiva no ensino escolar. Evidentemente, alguma alteração no cotidiano das escolas que se proponham a enfrentar o desafio de implementar práticas educativas contextualizadoras deverá ocorrer. Nesse sentido, processos de formação continuada em serviço ${ }^{12}$ podem ser planejados de modo que, ao potencializarem essa perspectiva curricular, também se aliem aos esforços de alterações do cotidiano das escolas.

\section{NOTAS}

${ }^{1} \mathrm{~A}$ investigação temática consiste na captação do universo temático de uma determinada comunidade escolar, sendo realizada pelos professores e a comunidade. Através do diálogo entre as partes, chega-se às situações relevantes. A investigação temática constitui-se de cinco etapas que envolvem uma equipe interdisciplinar, ou seja, são diferentes sujeitos envolvidos na apreensão das situações significativas da comunidade em questão. A $1^{\text {a }}$ etapa corresponde ao "levantamento preliminar" das condições gerais da comunidade na qual a escola está inserida. O levantamento é feito através de conversas informais com líderes da comunidade, alunos, pais de alunos, comerciantes da região, representantes de associações e até mesmo de dados escritos acerca da comunidade. A $2^{\mathrm{a}}$ etapa da investigação temática compreende a análise dos dados apreendidos na etapa anterior e a escolha das situações significativas para a comunidade. Entre essas situações, estão aquelas que correspondem às contradições sociais, além da preparação das "codificações" que serão exploradas na etapa seguinte. $\mathrm{Na} 3^{\mathrm{a}}$ etapa realiza-se um retorno à comunidade em que são feitas as descodificações dentro do círculo de investigação temática; é nesta etapa que se objetiva obter os temas. $\mathrm{Na} 4^{a}$ inicia-se a construção do programa a ser trabalhado em sala de aula, além da construção do material didático, constituindo a redução temática. A redução temática corresponde à visão das diferentes áreas na construção do material didático e do conteúdo programático. A última etapa equivaleria ao trabalho em sala de aula (DELIZOICOV, 1983).

${ }^{2}$ As situações-limite para Freire (2005) constituem-se em obstáculos que os sujeitos encontram para a compreensão e a realização de tarefas que os impedem de executá-las. O autor afirma ainda que as "situações-limites" não devem ser tomadas como barreiras insuperáveis, mas indicam a margem onde começam as possibilidades (FREIRE, 2005).

${ }^{3}$ Para Freire (2005), a práxis é o processo de ação e reflexão de forma indissociável.

${ }^{4}$ Um exemplo de tema-dobradiça sinalizado por Coelho (2010) é o carvão em uma cidade com histórico de contexto de mineração.

${ }^{5}$ Decisões tecnocráticas baseiam-se na concepção de eliminar os sujeitos de processos decisivos que envolvam ciência e tecnologia; caberia aos especialistas resolver todos os problemas de ordem científica e tecnológica.

${ }^{6} \mathrm{~A}$ esse respeito, ver Freire e Shor (1986).

${ }^{7}$ Freire não utiliza os termos "professores" e "estudantes", mas sim, "educadores" e "educandos". No entanto, ambas as designações são empregadas no contexto deste trabalho como sinônimos. Cabe destacar que os processos formativos, de modo geral, subentendem transformações. 
${ }^{8}$ Cabe destacar que o "logos" aqui referido não se reduz apenas a conhecimentos científicos específicos das áreas de atuação dos professores, mas também a outros conhecimentos, como pedagógicos, metodológicos e epistemológicos, por exemplo.

${ }^{9}$ No entanto, a transformação da realidade mencionada neste trabalho relaciona-se com a pedagogia progressista de Paulo Freire.

${ }^{10}$ Cumpre notar que muitos professores que adotam esse tipo de ensino não têm consciência, na maioria das vezes, de que são opressores, em razão de serem também oprimidos pelo sistema educacional que os formou. O educador também pode ocupar um nível de consciência ingênua e acreditar que a forma correta de trabalhar seja essa, e por isso, enfatiza-se a importância de se trabalhar esses níveis de consciência na formação inicial de professores. No entanto, a "opressão" também pode estar vinculada a convicções políticas educacionais dos educadores.

${ }^{11}$ Freire critica tanto visões salvacionistas quanto catastrofistas ligadas ao desenvolvimento científico e tecnológico: "Divinizar ou diabolizar a tecnologia ou a ciência é uma forma altamente negativa e perigosa de pensar errado" (FREIRE, 2006, p. 33). A visão salvacionista centra na ciência e na tecnologia a solução dos problemas da sociedade, de forma a proporcionar bem-estar social (AULER; DELIZOICOV, 2001).

${ }^{12} \mathrm{~A}$ respeito de elementos do processo formativo que possibilitam a contextualização à luz da abordagem temática no sentido freireano e a formação em serviço a partir da realidade atual do cenário educacional brasileiro recomenda-se a leitura de Coelho (2010).

\section{REFERÊNCIAS}

AULER, D. Alfabetização Científico-Tecnológica: um novo "Paradigma"? Ensaio: Pesquisa em Educação em Ciências, Belo Horizonte, v. 5, n. 1, p. 1-16, 2003.

AULER, D.; DELIZOICOV, D. Alfabetização científico-tecnológica para quê? Ensaio: Pesquisa em Educação em Ciências, Belo Horizonte, v. 3, n. 1, p. 105-115, 2001.

AULER, D.; DELIZOICOV, D. Ciência-Tecnologia-Sociedade: relações estabelecidas por professores de ciências. Revista Electrónica de Enseñanza de las Ciencias, Espanha, v. 5, n. 2, p. 337-355, 2006.

BRASIL, Ministério da Educação, Secretária de Educação Média e Tecnologia. Parâmetros Curriculares Nacionais: Ensino Médio. Brasília: Ministério da Educação, 1999. 109p.

BAZZO, V. Constituição da profissionalidade docente na educação superior: desafios e possibilidades. 2007. 269 f. Tese (Doutorado em Educação) - Faculdade de Educação, Universidade Federal do Rio Grande do Sul, Porto Alegre. 2007.

COELHO, C.J. Processos formativos para práticas transformadoras: temas-dobradiças como contribuição para abordagem temática. 2010. 473f Tese (Doutorado em Pós-graduação em Educação Científica e Tecnológica) - Programa de Pós-Graduação em Educação Científica e Tecnológica. Universidade Federal de Santa Catarina - UFSC, Florianópolis. 2010.

COELHO, C. J.; MARQUES, C. A. Contribuições freireanas para a contextualização no ensino de Química. Ensaio: Pesquisa em Educação em Ciências, Belo Horizonte, v. 9, p. 1-17, 2007.

CORTELA, B. S. C.; NARDI, R. Formadores de professores de Física: uma análise de seus discursos 
e como podem influenciar na implantação de novos currículos. In: IX Encontro de Pesquisa em Ensino de Física. Anais do IX EPEF. Jaboticatubas: SBF, 2004. p.11.

DELIZOICOV, D. Ensino de Física e a concepção freireana de educação. Revista de Ensino de Física, São Paulo, v. 5, n. 2, p. 85-98, dez. 1983.

. La educación en ciencias y la perspectiva de Paulo Freire. Alexandria, Florianópolis, v. 1, p. 37-62, 2008.

DELIZOICOV, D; ANGOTTT, A. J.; PERMAMUCO, M. M. Ensino de Ciências: fundamentos e métodos. São Paulo: Ed. Cortez, 2002.

DELIZOICOV, N. C.; STUANI, G. M.; DELIZOICOV, D. Reorientação curricular na concepção freireana de educação: análises em dissertações. Revista e-Curriculum, São Paulo. v. 3, p. 648-712, 2013. DELIZOICOV D. La educacion en ciencias y la perspectiva de Paulo Freire. Alexandria, Florianópolis. v. 1, p. 37-62, 2008.

FREIRE, P. Extensão ou comunicação? Rio de Janeiro: Paz e Terra, 1977.

. Pedagogia do Oprimido. Rio de Janeiro: Paz e Terra, 2005.

. Educação como prática da liberdade. Rio de Janeiro: Paz e Terra, 2006.

FREIRE, P.; SHOR, I. Medo e Ousadia. Rio de Janeiro: Paz e Terra, 1986.

GONÇALVES, F. P.; MARQUES, C. A.; DELIZOICOV, D. O desenvolvimento profissional dos formadores de professores de Química: contribuições epistemológicas. Revista Brasileira de Pesquisa em Educação em Ciências, São Paulo, v. 7, n. 3, p. 293-315, 2007.

HALMENSCHLAGER, K. R. Abordagem de temas em Ciências da Natureza no ensino médio: implicações na prática e na formação docente. 2014. 373f.Tese. Doutorado em Educação Científica e Tecnológica. Programa de Pós-Graduação em Educação Científica e Tecnológica. Universidade Federal de Santa Catarina, Florianópolis, 2014.

LEAL, M. C. Apropriação do discurso de inovação curricular em Química por professores do Ensino Médio. 2003. 295f. Tese (Doutorado em Educação). Faculdades de Educação. Universidade Federal de Minas Gerais. Belo Horizonte. 2003.

MUENCHEN, C.; DELIZOICOV, D. Os três momentos pedagógicos e o contexto de produção do livro física. Ciência e Educação, Bauru. v. 20, p. 617-638, 2014.

ODA, W. Y. A docência universitária em biologia e suas relações com a realidade das metrópoles amazônicas. 2012. 451f. Tese (Doutorado em Educação Científica e Tecnológica). Programa de Pós-Graduação em Educação Científica e Tecnológica. Universidade Federal de Santa Catarina, Florianópolis, 2012.

ODA, W. Y.; DELIZOICOV, D. Docência no Ensino Superior: as disciplinas Parasitologia e Microbiologia na formação de professores de Biologia. Revista Brasileira de Pesquisa em Educação em Ciências, São Paulo.v. 11, p. 101-122, 2011.

RICARDO, E. C. Competências, Interdisciplinaridade e Contextualização: dos Parâmetros curriculares Nacionais a uma compreensão para o Ensino de Ciências. 2005. 257f.Tese (Doutorado em Educação Científica e Tecnológica). Programa de Pós-Graduação em Educação Científica e Tecnológica. Universidade Federal de Santa Catarina, Florianópolis, 2005.

SANTOS, W. L. P. Contextualização no Ensino de Ciências por meio de temas CTS em uma perspectiva crítica. Ciências \& Educação, Bauru. v. 1, n. especial, p. 01-12, 2007.

Educação Científica Humanística em uma perspectiva Freiriana: resgatando a função do ensino CTS. Alexandria, Florianópolis. v. 1, n. 1, p. 109-131, 2008.

SANTOS, W. L. P; SCHNETZLER, R. Educação em Química: compromisso com a cidadania. Ijuí: Unijuí, 1997.

SILVA, A. F. G. A construção do currículo na perspectiva popular e crítica das falas significativas 
às práticas contextualizadas. 2004. 405 f. Tese (Doutorado em Educação), Pontifícia Universidade Católica de São Paulo. São Paulo. 2004.

O currículo na práxis da educação popular: projeto pedagógico interdisciplinar - temagerador via rede temática. In. PERNAMBUCO, M.; PAIVA, I. A. de. (Org.). Práticas coletivas na escola. Campinas: Mercado das Letras, 2013. p. 75-96.

TORRES, J. R.; FERRARI, N.; MAESTRELLI, S. R. P. Educação Ambiental crítico-transformadora no contexto escolar: teoria e prática freireana. In: LOUREIRO, C. F. B.; TORRES, J. R. (Org.). Educação Ambiental dialogando com Paulo Freire. São Paulo: Cortez, 2014. p. 13-80.

VIEIRA-PINTO, A. Consciência e Realidade Nacional. Rio de Janeiro: ISEB, 1960.

Data de envio: 05/02/2016

Data de aprovação: 29/05/2016

Data da versão final: 20/06/2016

\section{Contato:}

Carolina dos Santos Fernandes

Departamento de Metodologia de Ensino

Campus Universitário Trindade

Caixa Postal: 476

1 andar - Bloco B/CED

Trindade - Florianópolis, SC - Brasil

CEP: 88.040-900

carolferquimic@hotmail.com 